\title{
Successful anesthetic management of laparoscopic cholecystectomy in patients with situs inversus totalis
}

\author{
Mustafizur Rahman ${ }^{1 *}$, Deepankar Sarma² \\ ${ }^{1,2}$ Consultant, Dept. of Anesthesiology and Critical Care, Al-Salam Hospital, Assam, India \\ *Corresponding Author: Mustafizur Rahman \\ Email: mustaffizur@gmail.com
}

Received: $5^{\text {th }}$ December, 2018

Accepted: $1^{\text {st }}$ February, 2019

\begin{abstract}
Situs inversus totalis is a condition where visceral and thoracic organs are transposed from their normal anatomic position to the opposite and posed as mirror image. It is also a rare congenital condition. It may present some significant difficulty in diagnosing acute abdomen and in management of anesthesia also.Anesthesiologists must have a thorough knowledge regarding this condition and its associated abnormalities to conduct smooth anesthetic management. Here we are reporting three cases of situs inversus totalis posted for laparoscopic cholecystectomy under general anesthesia which went uneventful.
\end{abstract}

Keywords: Laparoscopy, Cholecystectomy, Situs inversus totalis, Kartazeners syndrome.

\section{Introduction}

Situs inversus totalis is a rare congenital condition in which a 270 degree clockwise rotataion of both abdominal and thoracic organs occurs during embryological development of organs resulting in a mirror image. ${ }^{1}$ Its incidence is around 1:5000 to 1:20000 among general population. ${ }^{2,3}$ It was Fabricius who first described situs inversus. ${ }^{4}$ Situs inversus totalis may be associated with cardiovascular anomalies like Transposition of Great Arteries, septal defects, respiratory anomalies like Kartageners syndrome which is a variant of Immotile cilia syndrome also called Primary Cilliary Dyskinesia. Situs inversus totalis, sinusitis, and bronchiectasis together in a patient, is known as Kartagener's syndrome. ${ }^{5}$ In $50 \%$ of patients situs inversus associated with kartageners syndrome. ${ }^{6}$ It may be also associated with splenetic anomalies. It may lend in diagnostic confusion in cases of acute cholecystitis, appendicitis, spleen lesions and myocardial infarction also. But the clinical scenario for management of anesthesia along with these associated conditions are extremely challenging for anesthesiologists.

\section{Case 1}

A 53 years female weighing $62 \mathrm{~kg}$, height $161 \mathrm{~cm}$, Mallampatti class 1 was posted for laparoscopic cholecystectomy. She was having pain in left hypochondrium for 2 months. Ultrasonography revealed chronic calculous cholecystitis with situs inversus. She was hypertensive on treatment with tab.olmesartan $40 \mathrm{mg}$ /hydrochlorthiazide $12.5 \mathrm{mg}$ and hypothyroid on thyroxine replacement $50 \mathrm{mcg}$. Her other laboratory parameters were normal. Chest x-ray and ECG revealed dextrocardia. CECT abdomen also showed situs inversus totalis with cholelithiasis. Echocardiography was normal with ejection fraction $67.33 \%$. On OT table ecg electrodes were placed in reverse manner. Premedication was done with inj.midazolam $1 \mathrm{mg}$, inj.glycopyrrolate $0.2 \mathrm{mg}$ and for analgesia infusion paracetamol $1 \mathrm{~g}$ with inj.tramadol $100 \mathrm{mg}$ was given. Esmolol 30mg and lignocaine 60mg intravenous given to blunt laryngoscopic sympathetic stimulation. Preoxygenation was done for 3 minutes followed by induction with inj.propofol
$150 \mathrm{mg}$ and after proper bag and mask ventilation inj.succynylcholine $90 \mathrm{mg}$ given for muscle relaxation. An endotracheal tube size $7.5 \mathrm{~mm}$ ID was placed and bilateral breath sounds confirmed by auscultation and air entry by ETCO 2 wave form. Anesthesia was maintained with O2:N2O 33:66, Isoflurane 0.5 to $1.5 \%$ and neuromuscular blockade by inj.atracurium. Surgery took half and hour. At the end of surgery neuromuscular blockade was reversed with inj.neostigmine and glycopyrrolate and patient was extubated smoothly. Perioperative period was uneventful.

\section{Case 2}

A 19years female, weighing $35 \mathrm{~kg}$, height $153 \mathrm{~cm}$, Mallampatti class 1 was posted for laparoscopic cholecyestectomy. Ultrasonography revealed chronic calculous cholecystitis with situs inversus. All other laboratory parameters were normal except ECG and chest X-ray revealed dextrocardia. She was also premedicated with inj.midazolam, inj.glycopyrrolate, inj.ondansetron and for analgesia inj.tramadol and infusion paracetamol were given. Patient was induced with inj.propofol and for neuromuscular blockade inj.atracurium was used. Anaesthesia maintained with O2:N2O 33:66 and Isoflurane $0.5-1.5 \%$. ETCO2 ranges were $32-46 \mathrm{mmHg}$. At the end of surgery residual neuromuscular blockade was reversed by inj.neostigmine and. inj glycopyrrolate and extubated normally.

\section{Case 3}

A 42 years female, weighing $70 \mathrm{~kg}$, height $167 \mathrm{~cm}$, Mallampatti class2 presented with the same setting of left hypochondrial pain for 20 days was posted for laparoscopic cholecystectomy. Her pre anesthetic check up was unremarkble except ECG and chest x-ray showed dextrocardia and ultrasonography revealed cholelithiasis with situs inversus. Echocardiography was normal. She was premedicated with inj.midazolam, inj.glycopyrrolate, inj.ondansetron and for analgesia inj.tramadol and infusion paracetamol were given intravenous. Patient was preoxygenated for 3 minutes and induced with inj.propofol and sevoflurane. For blunting 
laryngoscopic stimulation inj.lignocaine and inj.esmolol given intravenous in the dose of $1 \mathrm{mg} / \mathrm{kgBW}$ and $0.5 \mathrm{mg} / \mathrm{kgBW}$ respectively. A $7.5 \mathrm{mmID}$ endotracheal tube was placed in trachea after muscle relaxation with inj.succynylcholine. Maintenance of anesthesia was done with O2:N2O33:66, sevoflurane 1-2\% and inj.atracurium. Her ETCO2 ranges were $38-41 \mathrm{mmHg}$. Nitroglycerin infusion was started as her blood pressure was shot upto $180 / 100 \mathrm{mmHg}$ after 10 minutes of starting of surgery. At the end of surgery she was extubated normally with inj.neostigmine and glycopyrrolate.

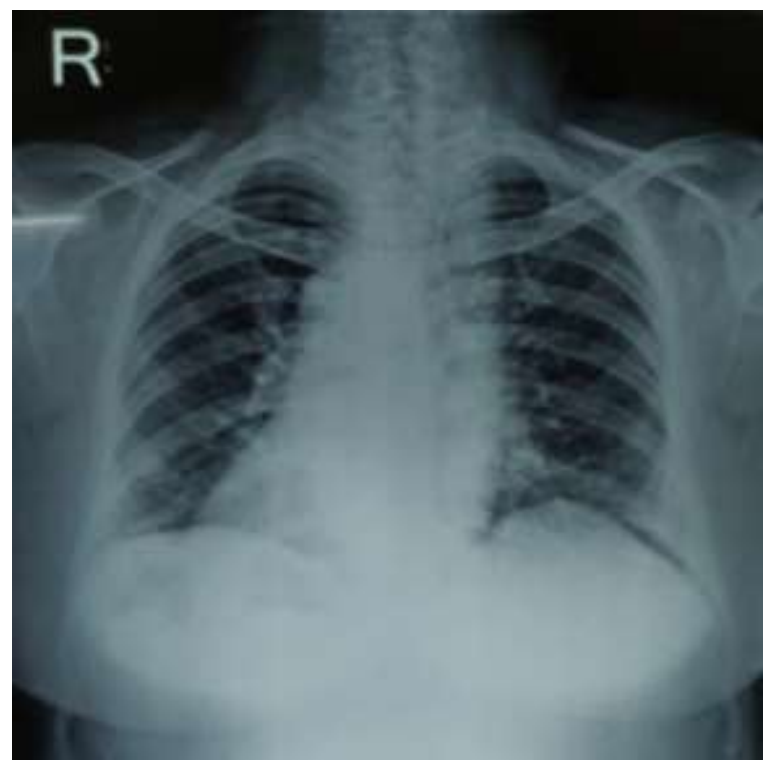

Fig. 1: Chest X-ray showing dextrocardia

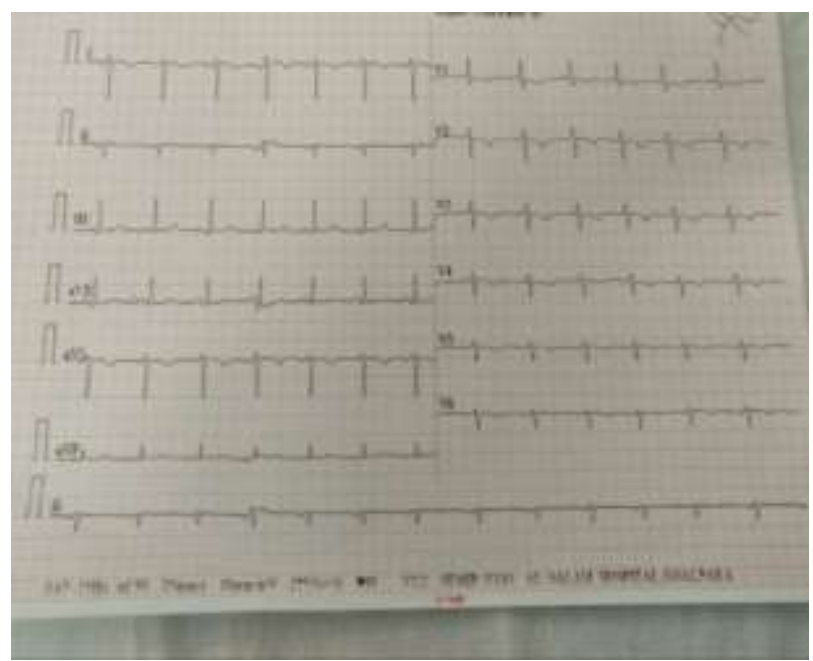

Fig. 2: ECG of dextrocardia

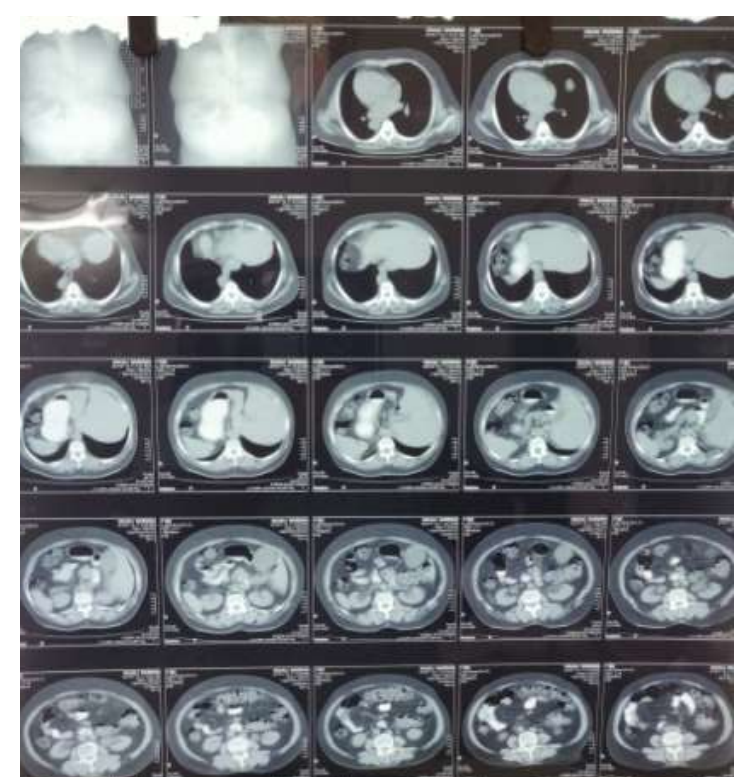

Fig. 3: CT scan showing dextrocardia with situs inversus

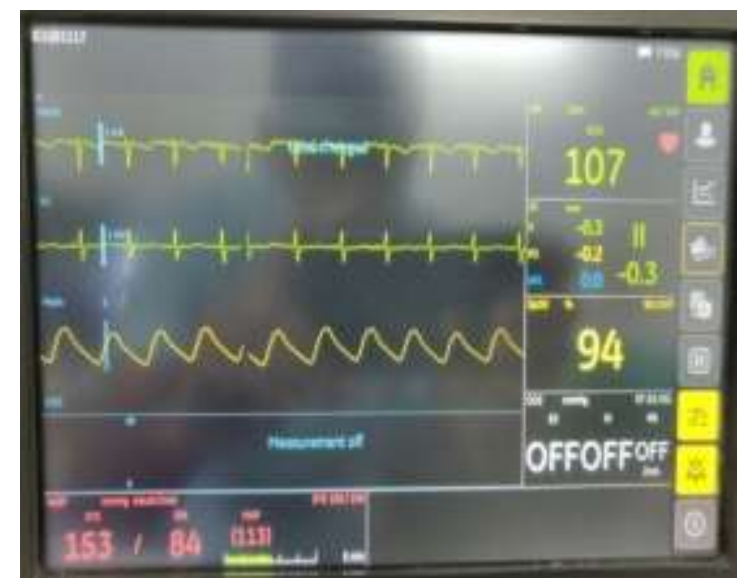

Fig. 4: Lead 2 showing QRS negative

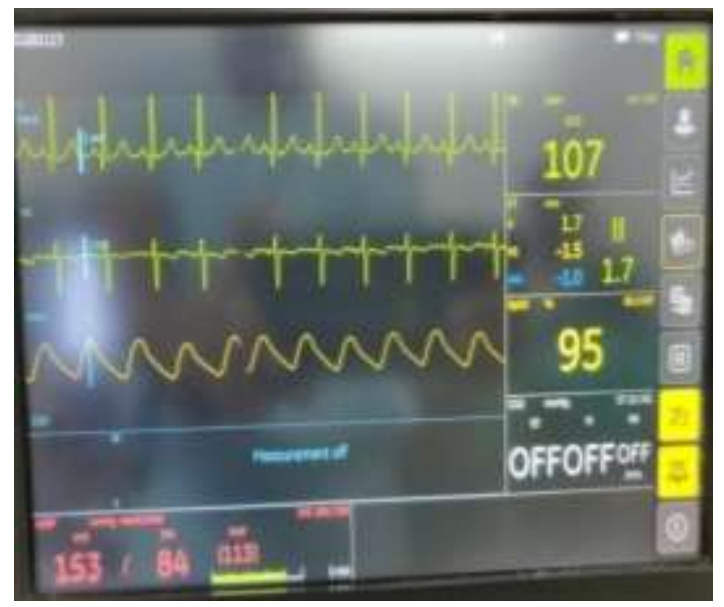

Fig. 5: ECG in lead 2 when electrodes placed in mirror image 


\section{Discussion}

Situs inversus totalis may be extremely challenging for the anesthesiologist if it is associated with other systemic anomalies. Here we would like to focus on a few important points which anesthesiologists must remember during planning of anesthetic management.

1. Clinical history is very important. Ask the patient if he/ she has recurrent cough or respiratory tract infection, pneumonia, any male sterility problem. If the answer is YES then it may be due to Primary Cilliary Dyskinesia or Kartegeners syndrome. CT-thorax and pulmonary function test may be advised for planning of anesthesia. Chest physiotherapy, bronchodilators, antibiotics, postural drainage also have important role in optimization prior to surgery. ${ }^{7}$

2. Since situs inversus totalis may be associated with cardiac anomalies like atiral septal defect, ventricular septal defect, transposition of great arteries, pulmonary valvular stenosis etc echocardiography must be done to rule out this anomalies. ${ }^{8}$

3. ECG electrodes must be placed on reverse direction to avoid diagnosing peri-operative ischaemia. ${ }^{9}$

4. In case of lung surgeries it may pose extreme difficulty in placing double lumen tube to separate the lungs. ${ }^{9}$

5. Situs inversus totalis may be associated with spinal deformities like split cord, meningomyelocele, spina bifida, scoliosis etc. So prior planning regional anesthesia these deformities must rule out. ${ }^{10}$

\section{Conclusion}

Anesthesiologists must have the precise knowledge and meticulous preparation about situs inversus totalis and its associated anomalies for the successful and safe anesthetic management.

\section{Conflict of Interest: None.}

\section{References}

1. Song JY, Rana N, Rottman CA. Laparoscopic appendicectomy in a female patient with situs inversus: Case report and literature review. JSLS 2004;8:175-7.

2. McKay D, Blake G. Laparoscopic cholecystectomy in situs inversus totalis: a case report. BMC Surg 2005;5:5.

3. Kumar S, Fusai G. Laparoscopic cholecystectomy in situs inversus totalis with left-sided gall bladder. Ann R CollSurg Engl 2007;89:W16-8.

4. Shivakumar M. Channabasappa, H. S. Mohan, and Jahanabi Sarma. A patient with situs inversus totalis presenting for emergency laparoscopic appendectomy: Consideration for safe anesthetic management. Anesth Essays Res 2013;7(1):127-9.

5. Franklin ME, Jr, Almeida JA, Reyes PE, Michaelson RL, Majarrez A. Cholecystectomy and appendectomy by laparoscopy in a patient with situs inversus totalis. A case report and review of the literature. Rev Mex Cir Endoscop 2001;2:150-3.

6. Anaesthesia for Kartagener's syndrome J. Reidy S. Sischy V. Barrow. BJA: Br j Anaesth, 2000;85(6):919-21.

7. Hazarika P, Das PP. Anesthetic management of a patient with situs inversus posted for laparoscopic cholecystectomy. Int J Res Med Sci 2017;5:4187-90.

8. Winer-Muram HT. Adult presentation of heterotaxic syndromes and related complexes. J Thorac Imaging 1995;10:43-57.
9. Bajwa, SJ, Kulshrestha, A, Kaur, J, Gupta, S, Singh, A, Parmar, SS The challenging aspects and successful anaesthetic management in a case of situs inversus totalis. Indian J Anaesth 2012;56:295-7.

10. Dwarakanath S, Suri A, Garg A, Mahapatra AK, Mehta VS. Adult complex spinal dysraphism with situs inversus totalis: A rare association and review. Spine (Phila Pa 1976) 2005;30:225-8.

How to cite this article: Rahman M, Sarma D. Successful anesthetic management of laparoscopic cholecystectomy in patients with situs inversus totalis. Indian J Clin Anaesth 2019;6(2):304-6. 